\title{
Causality Relationship between Foreign Direct Investment, GDP Growth and Export for Tanzania
}

\author{
Moses Joseph Shawa ${ }^{1} \&$ Yao Shen ${ }^{1}$ \\ ${ }^{1}$ School of Economics, Shanghai University, Shanghai, China \\ Correspondence: Moses Joseph Shawa, School of Economics, Shanghai University, 99 Shangda Road, 200444, \\ Shanghai, China. Tel: 86-135-6459-5972. E-mail:shamoses2002@yahoo.com
}

Received: May 24, 2013

doi:10.5539/ijef.v5n9p13
Accepted: July 31, $2013 \quad$ Online Published: August 26, 2013

URL: http://dx.doi.org/10.5539/ijef.v5n9p13

\begin{abstract}
Deep analysis on how foreign direct investment (FDI) interacts with the host country's GDP growth and export is very important for the identification of the strategies that will enable a developing country like Tanzania to achieve its development objectives. Hence we continue to analyze the causality relationship between FDI, Export and GDP growth of Tanzania for about 33 years starting from the year 1980 to 2012.In this study the co integration and granger causality test analysis is conducted. The co integration test reveals that there is existence of a long run association ship among the variables in questions. While the granger causality results suggests that there is a causality relationship which is unidirectional running from FDI to export and no causality was discovered between FDI and GDP growth suggesting that FDI is a good predictor of export and hence FDI led export growth for Tanzania might be necessary for the country to boost export.
\end{abstract}

Keywords: foreign direct investment (FDI), gross domestic product growth (GDPGR), export (EX), co integration test and granger causality, Tanzania

\section{Introduction}

In an effort to develop strategies and policy frameworks that will boost the economy of Tanzania to reach the developmental goals such as eradicating poverty. Tanzanian policy makers and academicians needs to know which variable among the three in question causes another so that the right strategies can be identified and well implemented that will have the major impact in the general economic development. Therefore Identifying the interrelationship between FDI, GDP growth and export is important in explaining the economic performance of the country particularly Tanzania.

From the past decades the study that focuses on the relationship between Export and GDP growth has been very important as evidenced by many researchers and discovered that these studies can help in understanding their impact and linkage on each other. In fact, the importance of FDI in the process of developing the economy of a country has been a very hot topic of discussion until recently. Efforts have been done by most developing nations mainly for the attraction of FDI by providing the conducive environment for the foreign investors as it has been one of the tool to bring capital that is insufficient to most developing nations.

In this case it seems reasonable to undertake studies of the linkage between FDI, GDP growth, and export. Since it has been observed from the fact that to the great extent these variables from theoretical point of view have the tendency to impact one another. Hence it is clear that without deep understanding of the direction of these variables it will be difficult to find the most effective policy for the sake of promoting the development of the country. Therefore it makes sense to analyze the causality relationship between these variables to make it easier in policy formulation in Tanzania.

In showing the linkage of FDI on GDP growth and export most studies have used the Granger Causality test as one of the method for analysis which will also be used for the analysis of the variable in question in this study.

This study follows three main stages of analyzing the three variables which are analysis of the stationarity of the variables in question, the test of co integration and finally employ the Granger causality test to find out the direction of the variables.

It should be noted that there are a lot of studies that explains relationship between FDI, GDP growth and export with very mixed results. Although to the best of my knowledge only few researches have been done basing on 
Tanzania economy.

The main objective to conduct this study is:

To provide the recent analysis of understanding the three variables in questions and add up to the existing literature while the specific objective is to find out the causal relationship of the variables for a case of Tanzania.

This study is organized into four parts. Part 1 covers introduction of the study,part two that covers the literature review which is followed by part 3 that Covers the Methodology of the study, data source and interpretation of the results part 4 covers Conclusion and policy recommendations.

\section{The Literature Review}

Generally, most of the previous empirical studies discovered that causality linkage between foreign direct investment (FDI), export and GDP growth to be so mixed. With Some researchers indicating the unidirectional response while others indicating the bi-directional response and remaining group find no response at all among the three variables in questions.

To see how those linkage between the variables in question is mixed observe the following studies.

The studies by M. Dritsaki, C. Dritsaki and A. Adamopoulos (2004) on the analysis of how FDI, export and economic growth relate to each other in Greece for the years between of 1960-2002 shows that the there is existence of a long run equilibrium relationship among the variables analyzed using the co integration test while Granger causality results shows a causal relationship existed on those variables. Miankhel, Thangavelu and Kalirajan (2009) did the causality test between FDI, export and GDP (economic growth) for Pakistan, India, Malaysia, Mexico, Thailand and chile.

Their findings were different for all the six nations .Their findings specifically reveal that economic growth attracts FDI in India in the long run that while GDP influence export in Pakistan.

The study shows that Thailand had a bidirectional relationship between FDI and GDP implying that FDI leads to GDP and hence GDP attracts FDI.

Dasgupta (2007) examined the long run impact of export, imports and FDI inflows on the outflows of FDI in India. His empirical results suggested the presence of Unidirectional causality running from the export and import to FDI out flows. The results found no causality existed from FDI inflows to the outflows.

According to the study by Syed Imran Ali Meerza (2012) on the investigation of the causal linkage between trade FDI and economic growth of Bangladesh between 1973 to 2008.In his study he found that in the co integration test there was a long run relationship on the variables being analyzed while he also found that economic growth influences both FDI and export and that there was the existence of a unidirectional causal relation between FDI and export which runs from export to FDI.

An empirical study by Shimul and Siddiqua (2009) found no existence of the linkage of FDI and GDP for Bangladesh for a period between 1973-2007.

Mohammad Sharif karimi (2009) using the methodology of Toda and Yamamoto examined the causal relationship between FDI and economic growth for a period between 1970 to 2005 and found no strong evidence of bi-directional causality between the two variables hence he suggested that FDI has an indirect effect on economic growth in Malaysia.

An empirical investigation of the study by Chow P. (1987) on the causal relationships between export growth and industrial development in eight newly industrializing countries found out that there is a strong bidirectional causality relationships between the export growth and industrial development which support the export led growth strategy in the sense that with the export expansion there will be the national income growth of the country.

Chakraborty and Basu (2002) Investigated on the relationship between economic growth and foreign direct investment (FDI) in India by employing the co integration and error correction model method and found out that there is unidirectional relationship with causation running from GDP to FDI and not otherwise.

In his study Athukorala (2003) on The Impact of FDI on Economic Growth in Sri Lanka showed that FDI inflows did not exert an independent influence on economic growth and the direction of causation was from GDP growth to FDI rather than FDI to GDP growth.

Many researchers have used the granger causality test to explore the linkage of the variables in question hence these studies employ the same methodology for the case of the developing country like Tanzania and observe directions of how these variables react towards one another. 
It should also be noted that most of the studies (some not covered in the literature review above) has been focused on the cross sectional data in their research for causality which is contrary on this study in the sense that it puts focus on one individual developing country of Tanzania which gives it an advantages of avoiding the problem of country's uniqueness behavior that would have happened incase other countries were involved for case of a cross section data analysis. In a cross section data analysis usually all countries involved are assumed to be homogeneous in their economical state. Another disadvantage is with the sensitivity in fixing up a model.

However according to other previous studies a panel data analysis can still capture a countries individual uniqueness behavior successfully incase more than one country is involved although it has been pointed out there is a possibility that it cannot explain to the great extent the influence of the variables which usually cannot be the same in different countries. Therefore for simplicity only Tanzania as one country will be analyzed in this study to determine the causation of the variables I question.

\section{The Methodology of the Study, Data Source and Interpretation of the Results}

In this study we employ the granger causality test for the estimation of the causality relation between FDI, GDP growth and export of Tanzania. The functional form is as shown below:

$$
E X=f(F D I, G D P G R)
$$

Note:

$\mathrm{EX}=$ Export

FDI=Foreign Direct Investment inflows

GDPGR $=$ Gross Domestic Product Growth

The measurement of export (EX) is taken as the real merchandise of export of Tanzania. Gross Domestic Product Growth (GDPGR) is taken as the real GDP growth rate annually and Foreign Direct Investment inflows (FDI) is taken as the FDI inflows to Tanzania.

The study uses the annual (secondary) time series data covering the period 1980-2012. This period has been chosen because data to be used in the foreign direct investment inflow is likely to be available. Most of these data were collected from the World Bank indicators covering the period between 1980-2012 annually.

The data are then put in logarithmic forms denoted by $\mathbf{l n}$ in each variable to avoid heteroscedasticity problem. The model involves the analysis of the relationship between GDPGR, FDI and export.

Once it is observed that the variables analyzed have the same trend and the first differences are also stationery in that case we can proceed with the process of co integration.

The preliminary step will be to find the order of integration by using the unit root tests. When it happens that the variables have a unit root then to become stationary we will have to differentiate the data on the first difference.

Then the following stage will be using the Johansen and Juselius co integration test to find the number of co integration. If the co integration is found then there is a need to test for Granger causality.

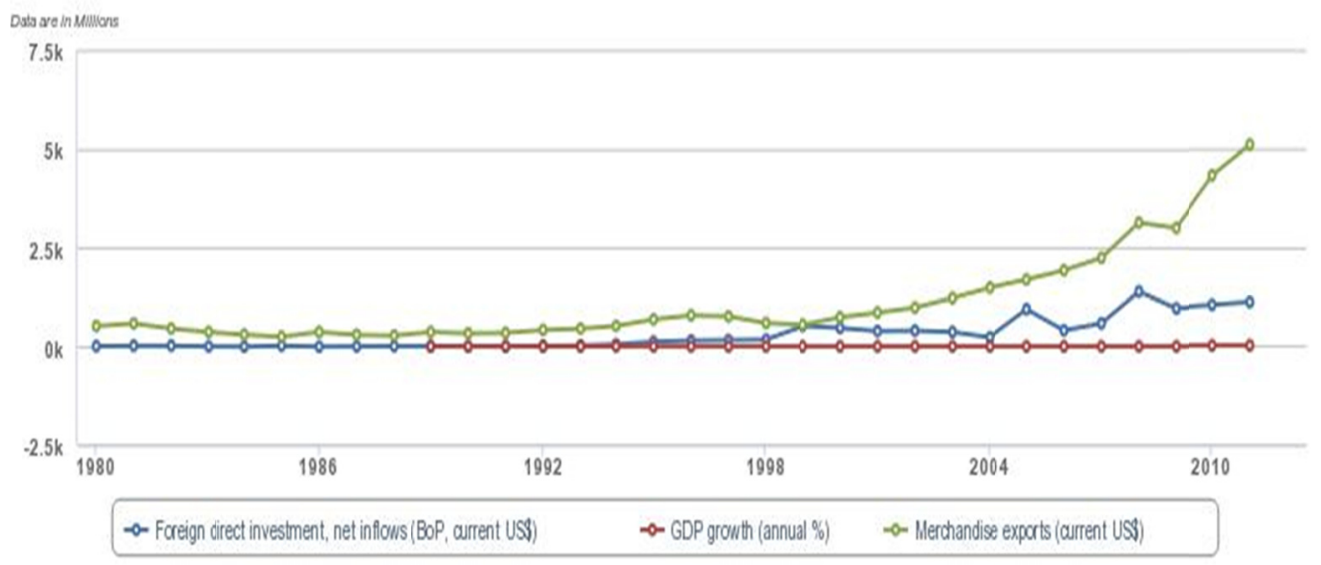

Figure 1. FDI inflows, GDP growth and export trend of Tanzania from 1980 to 2012

Source: world development indicators 2012 (WDI). 
Figure 1 above shows the trend of the three variables under investigation i.e. FDI inflows, GDP growth and export trend of Tanzania from the year1980 to 2012

\subsection{Augmented Dickey-Fuller (ADF)}

The ADF tests for the presence of a unit root of a variable $Y_{t}$, at time t. Where $\Delta$ the difference operator, the variable $Y_{t-i}$ indicates the first differences with $\mathrm{k}$ lags and $\varepsilon_{t}$ is the variable that makes adjustment of the errors of correlation. The coefficients $\beta$ is to be estimated for the variable $Y$. The hypothesis for the existence of a unit root in variable $Y_{t}$, is:

Null hypothesis; $\boldsymbol{\beta}=\mathbf{0}$.

Alternative hypothesis; $\boldsymbol{\beta} \neq \mathbf{0}$.

$$
\Delta Y_{t-1}=\alpha+\beta Y_{t-1} \sum_{j=1}^{k} \gamma_{i} \Delta Y_{t-k}+\varepsilon_{t}
$$

Table 1. Stationary (unit root) test for variables (ADF TEST)

\begin{tabular}{ccccc}
\hline \multirow{2}{*}{ Variables } & \multicolumn{2}{c}{ At level } & \multicolumn{2}{c}{ First differences } \\
\cline { 2 - 5 } & ADF Statistics & Critical Value & ADF Statistics & Critical Value \\
\hline \multirow{3}{*}{$\ln$ FDI } & 1.320841 & $1 \%-3.670170$ & $-8.160161^{*}$ & $1 \%-3.670170$ \\
& $(0.9982)$ & $5 \%-2.963972$ & $(0.0000)$ & $5 \%-2.963972$ \\
& & $10 \%--2.621007$ & & $10 \%--2.621007$ \\
ln GDPGR & -1.588418 & $1 \%=-3.653730$ & $-6.179983^{*}$ & $1 \%=-3.661661$ \\
& $(0.4768)$ & $5 \%=-2.957110$ & $(0.0000)$ & $5 \%=-2.960411$ \\
& & $10 \%=-2.617434$ & & $10 \%=-2.619160$ \\
$\operatorname{lnEX}$ & $-4.702082^{*}$ & $1 \%-3.670170$ & 1.548099 & $1 \%=-3.679322$ \\
& $(1.0000)$ & $5 \%-2.963972$ & $(0.9990)$ & $5 \%=-2.967767$ \\
& $10 \%--2.621007$ & & & \\
& &
\end{tabular}

Note: ${ }^{*},{ }^{* *},{ }^{* * *}$ indicates $1 \%, 5 \%, 10 \%$ level of significance respectively.

First of all we conduct the augmented Dickey-Fuller (ADF) unit root tests for each variable in a model which is a method developed by Dickey and Fuller (1979) testing for the significance of the independent variables . The results are presented in Table 1.

The augmented Dick Fuller results in table 1 shows that the two variables which are FDI (Foreign Direct investment) and GDPGR(Gross Domestic Product Growth) were not stationary at level but they became stationary after the first differences however the results found out that only one variables which is EX(Exports) was stationery at level hence in this case we follow Harris (1995), who made suggestion that the variables which integrated of different orders I(0), I(1) and I(2) may be co integrated especially when the theory supports that variable is relevant and that should be included on the research, LNEX is therefore considered in the regression model to proceed with the following steps in the analysis. Most of the time when the I (1) variables are put together, their linear combination will become I (1). On the other hand, when it happen that the variables have not the same order of integration, then in that case their combination will attain an order of integration of highest order (Brooks, 2008). Brooks indicated that a linear combination of I (1) variables will only become I (0), when the variables are co integrated.

\subsection{Johansen Co Integration Analysis}

The Johansen test is a method that can be used for testing co integration of several I (1) time series data. This test allows more than one co integrating relationship so is most widely used than other methods.

Generally two types of Johansen test are identified one is with trace and the other is eigenvalue .The null hypothesis to be tested for the case of trace test is there at most" $r$ "number of co integration vectors while the null hypothesis for the eigenvalue test is there " $r$ " co integrating vectors against the existence of alternative $\mathrm{r}+1$. The null hypothesis of no co integration against the presence of co integration is checked on this test. johansen and juselius (1990).

A general VAR (p) model can be depicted as:

If $x_{t}$ indicates a $\mathrm{k} \times 1$ vector that are not integrated in order higher than 1 , in that case $x_{t}$ can be represented as 
a Vector Auto regression of order $\mathrm{p}$ :

$$
X_{t}=\mu+\Phi D t+\Pi_{p} X_{t-p}+\ldots+\Pi_{1} X_{\mathrm{t}-1}+e_{t}, \mathrm{t}=1, \ldots, \mathrm{T}
$$

Where; $e_{t}$ residual term, $D_{t}$ deterministic term, $\Pi_{1}, u, \Pi_{\mathrm{t}-\mathrm{p}}$ matrices coefficients

Table 2. Johansen co integration tests

Series: LNFDI LNGDPGR LNEX

\begin{tabular}{ccccc}
\hline \multicolumn{5}{c}{ Test (Trace) } \\
\hline Hypothesized no of CE(s) & Eigen value & Trace Statistics & 0.05 Critical value & Prob. ${ }^{* *}$ \\
None * & $\mathbf{0 . 9 3 0 5 7 4}$ & $\mathbf{7 7 . 6 7 5 3 4}$ & $\mathbf{2 9 . 7 9 7 0 7}$ & $\mathbf{0 . 0 0 0 0}$ \\
At most 1 & 0.259432 & 8.320411 & 15.49471 & 0.4318 \\
At most 2 & 0.019486 & 0.511641 & 3.841466 & 0.4744 \\
\hline \multicolumn{5}{c}{ Test (Maximum Eigen value) } \\
\hline Hypothesized no of CE(s) & Eigen value & Max Eigen Statistics & 0.05 Critical value & Prob. ** \\
None * & $\mathbf{0 . 9 3 0 5 7 4}$ & $\mathbf{6 9 . 3 5 4 9 3}$ & $\mathbf{2 1 . 1 3 1 6 2}$ & $\mathbf{0 . 0 0 0 0}$ \\
At most 1 & 0.259432 & 7.808769 & 14.26460 & 0.3985 \\
At most 2 & 0.019486 & 0.511641 & 3.841466 & 0.4744 \\
\hline
\end{tabular}

Source: world development indicators 2012(WDI).

Note; both trace and max Eigen test indicates 1 co integrating eqn (s) at the 0.05 level.

In conducting this test the number of lags determination is very important therefore by selecting Akaike information criterion and Schwarz criterion an optimal number of lags 6 is achieved hence on performing the co integration test we get 1 co integration vector from both the trace statistics and eigenvalue statistics at 5 percent level. Table 2 indicates the results.

\subsection{Analysis of the Granger Causality Test}

We perform the Granger-Causality test in order to examine whether one economic variable is useful in forecasting another in short-run. In this study, we employ the method developed by (Granger, 1969). If we assume two variables e.g. $X_{t}$ and $Y_{t}$, affect each other with some lags. The relationship of these two variables can be formulated in a VAR model .Then, if we test whether $X_{t}$ causes $Y_{t}$, we check that how much of the present $Y_{t}$ can be represented by lagged values of $Y_{t}$ and $X_{t}$. In the Granger causality we check the null hypothesis that $X_{t}$ does not granger cause $Y_{t}$; and if we can reject the null hypothesis, it implies that $X_{t}$ does Granger cause $Y_{t}$. As Granger-causality tests require stationary data therefore all the variables have to be tested for the existence of unit roots. Only when we fail to find the presence of a unit roots estimation models will be conducted with only long-run coefficients to be used for the estimation hence, the estimate of a VAR model will be as follows.

$$
\begin{gathered}
X_{t}=\sum_{i=1}^{m} \alpha_{i} X_{t-i}+\sum_{j=1}^{m} \beta_{j} Y_{t-j}+\mu_{t} \\
Y_{t}=\sum_{i=1}^{n} \lambda_{i} Y_{t-i}+\sum_{j=1}^{n} \delta_{j} X_{t-j}+\varepsilon_{t}
\end{gathered}
$$

Where $X_{t}$ and $Y_{t}$ indicates the variables to be estimated at time t.The $u_{t}$ and $\varepsilon_{t}$ are the residual prediction errors which are uncorrelated to each other. Equation 4 depicts the variable $\mathrm{x}$ is decided by a lagged variable of $\mathrm{Y}$ and $\mathrm{X}$.the same applies to equation 5 except that in this equation its dependent variable is represented by a variable $\mathrm{Y}$ instead of X. In this test usually we check if the estimated lagged coefficient $\alpha_{i}$ are $\lambda_{i}$ different from zero by using the F-statistics. When the jointly test rejects the two null hypothesis that $\alpha_{i}$ and $\lambda_{i}$ are both different from zero, then in that case the casual relationships between $\mathrm{X}$ and $\mathrm{Y}$ are confirmed. Generally speaking granger causality has been used by many researchers for investigation of the causal relationship although it is not without limitations for example being sensitive to the number of lags to be used and the model specifications as pointed out by Gujarat (1995). So it must always be used with care.

Following is the results of the granger causality test as indicated by table no. 3 below 
Table 3. Pair wise Granger causality test

\begin{tabular}{ccccc}
\hline Null Hypothesis & Obs & F-Statistic & Prob. & Conclusion \\
\hline lnGDPGR does not Granger Cause LNFDI & 26 & 0.24537 & 0.9634 & \\
lnFDI does not Granger Cause LNGDPGR & & 0.31893 & 0.9300 & \\
lnEX does not Granger Cause LNFDI & 26 & 1.58632 & 0.2371 & \\
InFDI does not Granger Cause LNEX & & $\mathbf{3 . 8 3 4 7 7}$ & $\mathbf{0 . 0 2 3 4}$ & InFDI $\rightarrow$ InEX \\
lnEX does not Granger Cause LNGDPGR & 26 & 1.09573 & 0.4279 & \\
lnGDPGR does not Granger Cause LNEX & & 1.22962 & 0.3642 & \\
\hline
\end{tabular}

Source: world development indicators 2012(WDI).

The Granger causality test results shows that the causal unidirectional relationships exist only between FDI and Export with the direction running direct from FDI to export which imply that FDI is can be used in forecasting Export growth in Tanzania although in reality it is hard to find this evidence for the case of Tanzania as we have not seen any significant impact of FDI on export in the economy of Tanzania which raise questions on the motives of foreign investors to Tanzania or some other factor might have an influence on export. This finding collaborates with the findings of M. Dritsaki, C. Dritsaki and A. Adamopoulos (2004) and Samsu et al. (2008). However, this result contradicts with that found by study by Syed Imran Ali Meerza (2012) for Bangladesh. All in all this study still support the FDI led export growth for Tanzania as evidenced by the results although care must be taken on the motives of multinational company intending to invest in Tanzania.

Despite the fact that FDI is known to be the most contributing factor for GDP growth of the country, this study has not find any evidence to prove this for the case Tanzania as we can see from the results that no causation between FDI and GDP growth which supports the results obtained by Mohammad Sharif karimi (2009).

\section{Conclusion and Policy Recommendations}

The study has been conducted using the annual data spanning from 1980 to 2012 for the sake of identifying the causality relation between FDI, GDP growth and export of Tanzania. We first started with the test of stationarity of the three variables in question using augmented Dickey-Fuller (ADF) test and the results showed that the two variables which are FDI(Foreign Direct investment) and GDPGR(Gross Domestic Product Growth) were not stationery at level but they became stationery after the first differences however the results found out that only one variables which was EX(Exports) to be stationery at level hence in this case we followed Harris (1995:80), who made the argument that the variables which are integrated of different orders i.e I(0), I(1) and I(2) may be co integrated especially when the theory supports that variable is relevant and that should be included on the research, since LNEX was an important variables in this study and was therefore taken in the regression model to proceed with the next steps of the co integration analysis.

The co integration test found one co integration equation on both the max-Eigen and Trace statistics implying the existence of a long run association ship on the variables in question. While the granger causality test results showed that there is a causality relationship which is unidirectional running from FDI to export and no causality was found between FDI and GDP growth suggesting that more policies to attract FDI is important to boost export, the results also implies that either FDI or GDPGR cannot be used to predict one another since no significant causal relationship was found between the two. However the study suggests that Multinational Company motives should be taken into consideration if FDI led export growth has to bring the desired results basing on the reality situation in Tanzania.

The findings of this study may contribute to the existing literature especially for Tanzania and other developing countries on the factors in questions when it comes to policy making in the country. The research is also limited basing on the fact that the data for Tanzania are not so exhausted therefore interpretation should be done with care and further studies should focus on those limitation that might bring a more robust results for the case of Tanzania.

\section{References}

Akaike, H. (1973). Information theory and an extension of the maximum likelihood principle. In Petrov, B., \& Csaki, F. (Eds.), 2nd International Symposium on Information Theory. Budapest, Academia Kiado.

Athukorala. (2003). The impact of foreign direct investment on economic growth in Sri Lanka. Sri Lankan Journal of Agricultural Economics, 6(1).

Brooks (2008). Introductory econometrics for finance. 
Chow, P. (1987). Causality between export and industrial development. Journal of Development Economics, 26, 55-63. http://dx.doi.org/10.1016/0304-3878(87)90051-4

Dasgupta, N. (2009). Examining the long run effects of export, import and FDI inflows on the FDI outflows from India: A causality analysis. Journal of International Business and Economy, 10(1), 65-88.

Dickey, D. A., \& Fuller, W. A. (1979). Distributions of the estimators for Autoregressive time series with unit root. J. American Stat. Assoc., 74, 427-431. http://dx.doi.org/10.2307/2286348

Dritsaki, M., Dristaki, C., \& Adamopoulos, A. (2004). A causal relationship between trade, foreign direct investment and economic growth of Greece. American Journal of Applied Sciences, 1, 230-235. http://dx.doi.org/10.3844/ajassp.2004.230.235

Granger, C. W. (1988). Some recent developments in a concept of causality. J. Econometrics, 39, 99-211. http://dx.doi.org/10.1016/0304-4076(88)90045-0

Granger, C. W. J. (1969). Investigating causal relations by econometric models and cross spectral method. Econometrica, 37(3), 424-438. http://dx.doi.org/10.2307/1912791

Gujarati, D. (1995). Basic econometrics (3rd ed.). Singapore: McGraw-Hill.

Harris, R. (1995). Using co integration analysis in econometric modeling. London: Prentice Hall.

Johansen, S., \& Juselius, K. (1990). Maximum likelihood estimation and inference on co integration with applications to the demand for the money. Oxford Bulletin of Economics and Statistics, 52, 169-210. http://dx.doi.org/10.1111/j.1468-0084.1990.mp52002003.x

Meerza, S. I. A. (2012). The causal links between trade, foreign direct investment and economic growth for Bangladesh. Working paper.

Miankhel, A. K., Thangavelu, S. M., \& Kalirajan, K. (2009). Foreign direct investment, export and economic growth in South Asia and selected emerging countries: A multivariate VAR analysis. Working paper 23, Centre for Contemporary Asian Studies, Doshisha University.

Mohammad, S. (2009). FDI and economic growth in Malaysia. University of putra Malaysia.

Shimul, S. N., Abdullah, S. M., \& Siddiqua, S. (2009). An examination of FDI and growth nexus in Bangladesh: Engle and granger and bound testing co integration approach. BRAC University Journal, 1(1), 69-76.

\section{Copyrights}

Copyright for this article is retained by the author(s), with first publication rights granted to the journal.

This is an open-access article distributed under the terms and conditions of the Creative Commons Attribution license (http://creativecommons.org/licenses/by/3.0/). 